Distribution Category:

Magnetic Fusion Energy

(UC-20)



ANL/FPP/TI -173

ANL/FPP/TM-173

DE83 012381

ARGONNE NATIONAL LABORATORY

9700 South Cass Avenue

Argonne, Illino1s 60439

IHIOR IIPURITI-CONTROL AND FIRST-DALL STSTHA

by

MOHAYED A. ABDOU

Fusion Power Program

Apr11 1983

\title{
DISCLAIMER
}

This report was prepared as an account of work sponsored by an agency of the United States Government. Neither the United States Government nor any agency thereof, nor any of their employees, makes any warranty, express or implied, or assumes any lezal liability or reaponsibility for the accuracy, completenese, or usefulness of any information, apparatus, product, or process discloced, or represents that its use would not infringe privately owned rights. Reference herein to any specific commercial product, procest, or service by trade name, trademark, manufecturer, or otherwise does not necessarily constitute or imply it endorsement, recommendation, or favoring by the United States Government or any asency thereof. The view and opinions of authors exprased herein do not necestarily state or reflect thoue of the United States Government or any agency thereof. 


\section{Table of Contente}

\section{Page}

ABSTRACT 1

1. Itrronoctron. $\ldots \ldots \ldots \ldots \ldots \ldots \ldots \ldots \ldots \ldots \ldots \ldots \ldots \ldots \ldots \ldots \ldots \ldots \ldots \ldots \ldots \ldots \ldots \ldots \ldots \ldots \ldots$

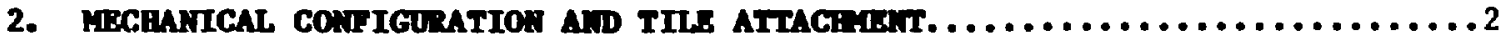

3. EROSION RECHANISIMS AND REDSPOSTTION. ..........................4

3. 1 Physical Sputtering and Dependence on Plasma Edge Temperature.......4

3.2 Chemical Sputtering................................

3.3 Plasma Disruption...................................6

3.4 Arcing............................................

3.5 Net Erosion/Redeposition Rates............................8

3.6 LImiter Leading Edge SolutIons.............................9

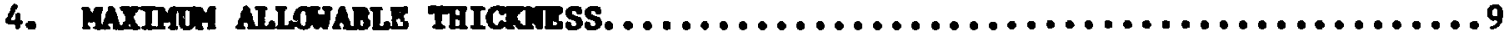



6. PHYSICS ASPECTS OF PLASA EDE TEIPERATURB......................15

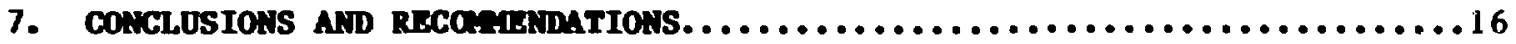

References.....................................................19 


\section{List of Mgure}

Mgure th.

1

2

3

4

5.

Table lo.

1

2

3

4

5
Ittle

Fage

Pololdal divertor configuration.....................

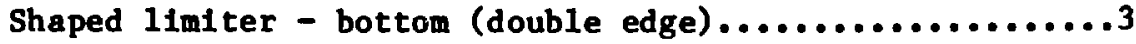

Temperature dependence of the chemical sputtering yleld of papyex graphite (from Roth, Bohdansky and W1180n)....................................7

Erosion (physical sputtering only) and redeposition rates for beryllium as a function of spatial points at the IImfter surface for a plasma-edge temperature

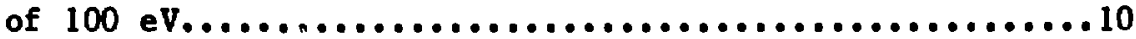

Maximum tile temperature vs. thickness for varlous tile materials at the top surface of limiter/divertor with perfect contact between the tile and copper heat sink.......................................12

\section{List of Tables}

TItle

Page

PLASMA-EDGE TEMPERATURE $\left(\mathrm{T}_{e}\right)$ REGIMES THAT MINIMIZE

PHYSICAL SPUTTERING, .........................5

VAPORIZED AND WELT REGION THICKNESSES, MICRONS PER DISRUPTION (INITIAL TEMPERATURE IS $300^{\circ} \mathrm{C}$ )...........7

NET EROSION RATES (REPRESENTATIVE VALUES) $(\mathrm{cm} / \mathrm{y})$

(507 AVAILABILITY, $80 \%$ DUTY CYCLE) ................10

MAXIMUM ALLOWABLE THICKNESS OF PLASMA-SIDE MATERIALS.....12

LIFETIME (YEARS) DURING STAGE III (50\% AVAJLABILITY

FOR DIVERTOR/LIMITER TOP SURFACE ( $\mathrm{V}-15 \mathrm{Cr}-5 \mathrm{~T} 1$ HEAT

SINK).........................................14 


\title{
IHIOR IMPURITI CONTROL AND FIRST WALL STSTEA
}

by

Mohamed A. Abdou

\begin{abstract}
The highlights of the recent INTOR effort on examining the key issues of the impurity control/first wall system are summarized. The emphasis of the work was an integrated study of the edge-region physics, plasma-wall interaction, materials, engineering and magnetic considerations associated with the poloidal divertor and pump limiter. The development of 1 imiter and divertor collector plate designs with an acceptable lifetime was a major part of the work.
\end{abstract}

\section{INTRODOCTION}

A comprehensive effort was devoted to examining the critical issues of the impurity control system for'INTOR. The details of the investigation are available in Ref. 1. The efforts by the four INTOR-participating countries are documented in Refs. 2-5. This paper summarizes the key results.

The primary emphasis of this work was an integrated study of the edgeregion physics, plasma-wall interaction, materials, engineering and magnetic considerations associated with poloidal divertor and pump limiter. The most critical problem concerns the lifetime of the limiter and divertor plate. The lifetime tends to be short because of the rapid erosion and the relatively small thickness of the surface material that can be allowed under high heat flux conditions. Erosion mechanisms were examined in detail. The dependence of physical-sputtering erosion on the plasma-edge temperature was examined. Plasma transport calculations were performed to determine the probable values of the plasma-edge temperature. Detalled lifetime estimates of the limiter and divertor collector plates were carried out for a number of materials and a wide range of operating conditions.

The general design requirements for the Impurity control system were translated into the following specific requirements for the INTOR conditions:

1. Under low radiation conditions the limiter or divertor must absorb $80 \mathrm{MW}$ of thermal load durling the burn phase. If a high radiation condition proves credible, then the power loading can be substantially reduced with a minimum level, dictated by the fraction of radiated power impinging on the limiter or divertor.

2. The 1imiter or divertor must withstand the deposition of $80 \mathrm{MJ}$ of thermal energy during plasma disruptions, with a frequency of 5 disruptions per 1000 plasma burn cycles during Stage I of INTOR operation, and one disruption per 1000 burn cycles during Stages II and III.

3. The impurity control system must limit the helium buildup within the discharge to about $5 \%$. This translates to the removal of $2-4 \%$ of the recycled gas. 
4. The impurity control system wast minimize the impurity contanination and associated central radiation to a level where it does not dominate the power balance. This translates to the following levels of contanination. Impurities with atomic numbers $2<Z<10$ (10w-Z) must be kept below $1 \%$ of the electron concentration; Impurities with atomic numbers $10<\mathrm{Z}<30$ (medium-Z) must be kept below 0.17 and those with $Z>30$ (h1gh-Z) must be kept below $0.01 \%$.

\section{HCGANICAL CONFIGURATION AND TILE ATTACHAitT}

The configuration of a pololdal divertor is shown in Fig. 1. A single null is located at the bottcon of the plasma chamber with a continuous toroldal opening extending around the reactor. The outer and inner divertor plates are placed at angles of $15^{\circ}$ and $30^{\circ}$, respectively, to the separatrix. Both plates are flat with a peak heat flux of $\sim 2.4 \mathrm{MW} / \mathrm{m}^{2}$.

The ilmiter configuration is shown in Fig. 2. The limiter is located at the bottom of the plasma chamber and extends toroldally around the entire chamber.

The limiter is a concave shape facing the plasma with two pumping channels, and hence two leading edges. The limiter is shaped to reduce the peak heat flux on the front surface to $\sim 2.4 \mathrm{MW} / \mathrm{m}^{2}$. Depending on the scrapeoff region physics conditions, a flat limiter may result in a much higher peak flux at the top surface. A two pumping channel configuration is preferred over the one-channel 11miter because, for the same pumping requirements, the heat load on the critical leading edge region can be substantially reduced. The peak heat flux on the leading edge is $\sim 1 \mathrm{MW} / \mathrm{m}^{2}$. The overall width of the limiter blade is $145 \mathrm{~cm}$.

The first wall is made of austenitic stainless steel with corrugatedpanel type construction. Armor on the first wall is used only in local areas such as the charge-exchange (CX) regions. In the reference limiter case, the heat flux to the first wall is $\sim 10 \mathrm{~W} / \mathrm{cm}^{2}$ except in the $\mathrm{CX}$ reglons where $1 \mathrm{t}$ peaks at $\sim 2 \mathrm{j} / \mathrm{cm}^{2}$. For the divertor case, the heat flux to the first wall is $\sim 12 \mathrm{~W} / \mathrm{cm}^{2}$.

Protective coating/cladding, probably in the form of tiles are required on the plasma side of the limiter, divertor plates and special areas of the first wa11. The attachment of these tiles to the actively cooled substrate (normally referred to as heat sink for 11miter and divertor) is a critical 1ssue as it greatly impacts the performance and rellabllity of the engineering design. Tisree basic attachment schemes with a number of variations were examined. The first method is a positive attachment that results in a high thermal conductance across the interface between the tiles and heat sink. The advantage of the high-conductance attachment 18 that it keeps the tile temperatures low and therefore 1 ts usefulness extends to a large number of materials, particularly temperature-1imited materials such as berylliu. The main drawback of this concept 18 the high stresses induced in the heat sink and in the tile-substrate interface. This problem can be mitigated, to some extent, by design considerations such as reducing the size of the tiles.

The second concept is a mechanfcal attachment with practically no thermal conduction across the interface. The operating tenperatures of the tiles are 


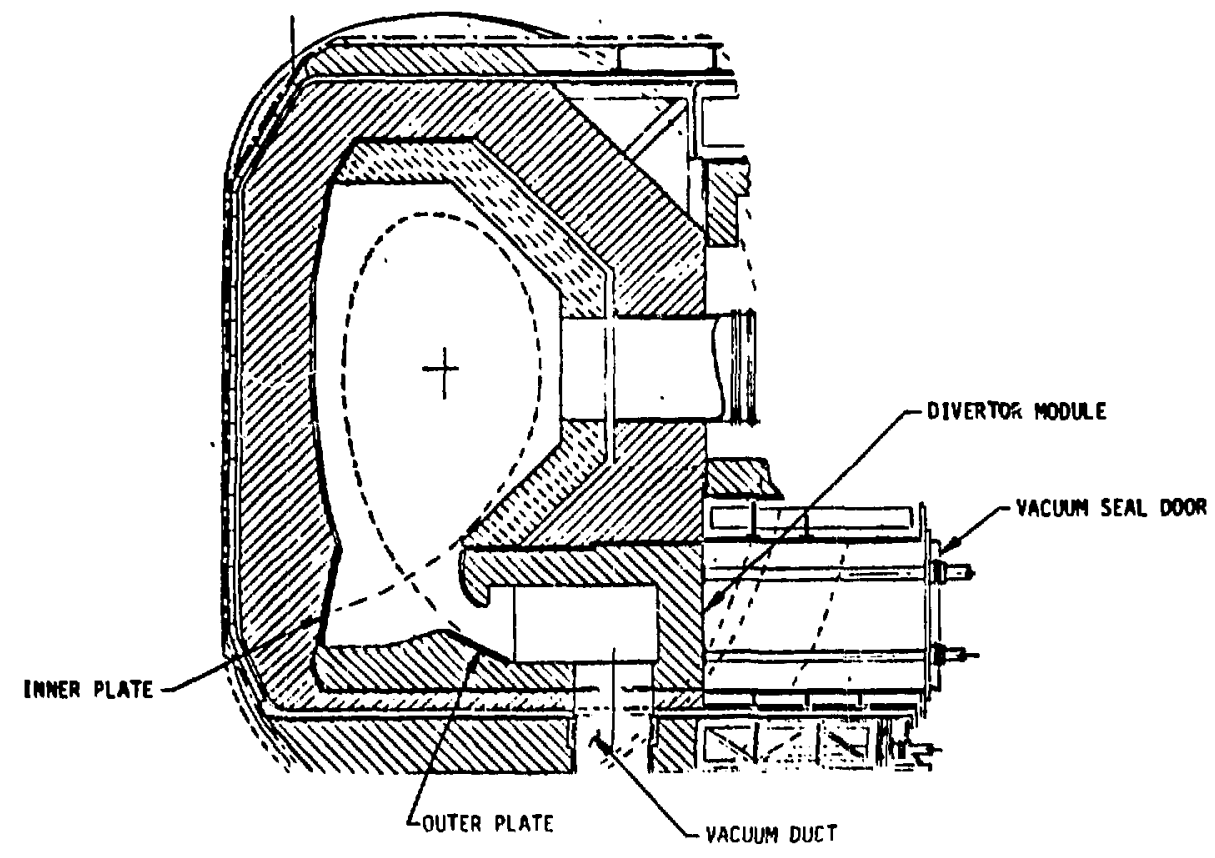

Figure 1. Poloidal divertor configuration.
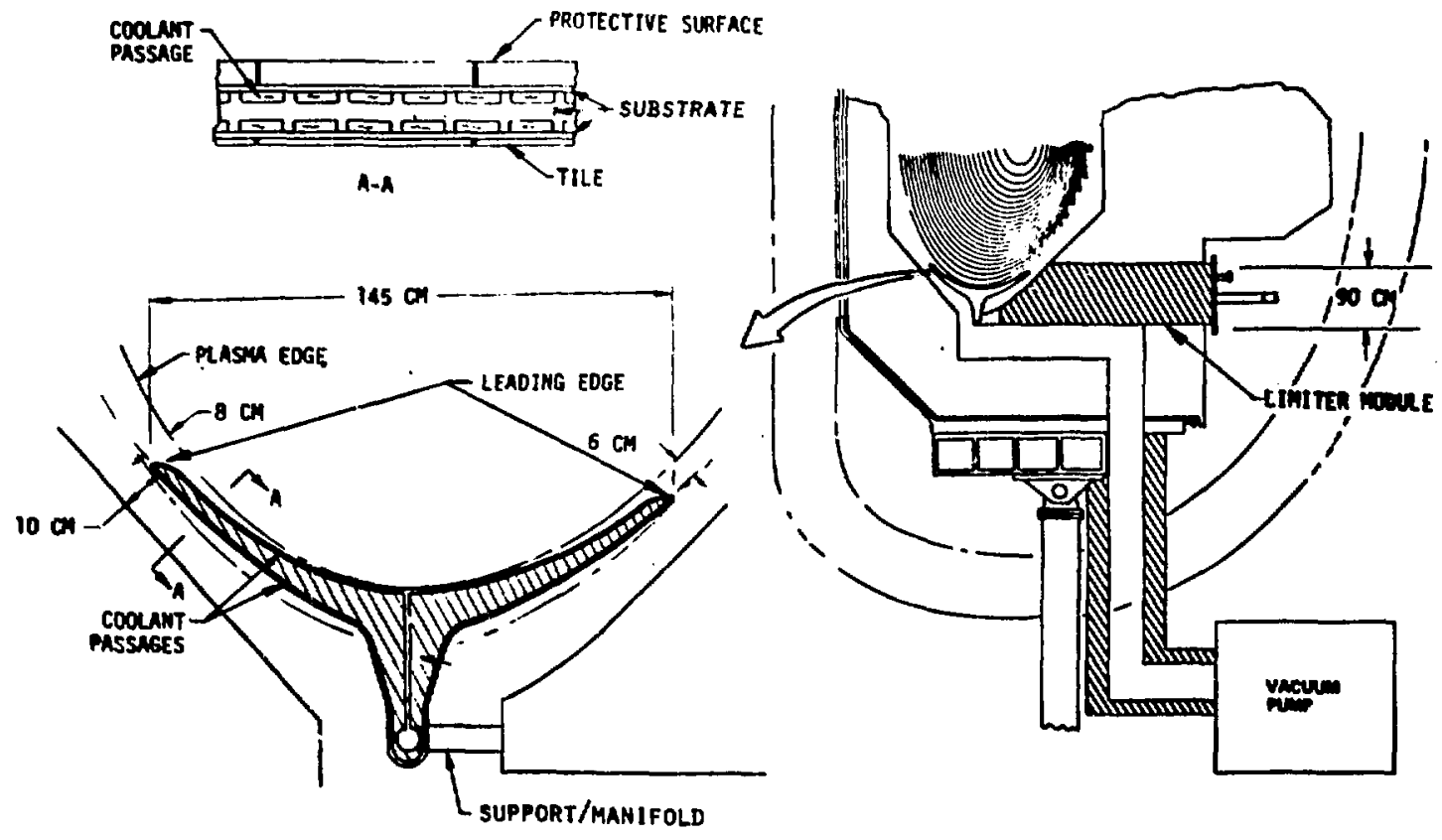

Figure 2. Shaped limiter - bottom (double edge). 
typically high $\left(>2000^{\circ} \mathrm{C}\right)$ with radiation cooling from both sides. The main advantage of this concept is that it eliminates interface stresses. However, the resultant high temperatures of the tiles limit the usefulness of this concept to ingh-temperature materials such as tungsten and tantalum.

A third concept is to use a fiber metal complinnt layer brazed between the tiles and substrate. This offers the possibility of using an attachment with predictable thermal conductance with low interface stresses. There are several types of compliant-type fibers presently in use. The major concern is the effect of radiation on the compliant layer.

The high-conductance attachment concept is recommended as the reference concept. However, the compliant-layer approach is worthy of future investigation.

\section{EROSION MECBANISHS AND REDEPOSIYION}

The lifetime of the limiter and divertor plates is 1imited primarily by erosion. The four erosion mechanisms of concern are: 1) physical sputtering, 2) chemical sputtering, 3) vaporization and loss of melt layer during plasma disruptions, and 4) arcing. The results of examining these four erosion mechanisms are discussed below followed by estimates of net erosion and redepositinn rates.

\section{1 Physical Sputtering and Dependence on Plasa Edge Tepperature}

Physical sputtering by energetic plasma particles (D, T, He) is generally the dominant erosion mechanisms for most materials. The sputtering yield typically peaks at a few hundred electron volts for low $Z$ materials and a few thousand electron volts for high-Z materials.

Most atoms sputtered from the surface of the limiter and divertor will be lonized and returned back along the field lines to the limiter/divertor surface. Thus, self sputtering is of concern. of critical importance is the energy at which self sputtering exceeds unity. A self-sputtering yleld greater than unity will result in a sputtering cascade with the effective sputtering yield reaching infinity in theory (other effects will eventually limit the effective sputtering yield). For low-Z materials, self-sputtering is $<1$ at all incident ion energies. Medium- and high-Z materlals have a self-sputtering yleld that exceeds unity at Ion energies greater than $\sim 400-$ $800 \mathrm{eV}$.

An assessment of the physical sputtering ylelds was conducted. Considerable experimental data exists for normal-incidence 11ght-1on ( $D$, He) sputter1ng. The uncertalnty factor in the sputtering yleld is estimated to be about a factor of two. No experimental data exists for tritium sputtering yield. Very little data exists for self sputtering. Therefore, self-sputtering ylelds are estimated based primarily on extrapolarion of sputtering data for Inert gas lons of similar mass. New experimental sputtering data, particularly for self sputtering is needed. The energy at which self sputtering exceeds unity should be determined to a high accuracy. Self-sputtering yields are more difficult to predict for compounds. It is not possible at present to determine whether self-sputtering ylelds for SIC can exceed unity. It is predicted that the self-sputtering yield for BeO will remain less than unity at all Ion energles. 
Of particular importance to this work is to correlate the energy of the Ions incident on the liniter/divertor surface to the plasma edge temperature $\left(T_{e}\right)$. Accounting for a sheath potentlal of $\sim 3 T_{e}$, the peak hydrogen (D, $T$ ) Ion energy at the limiter/divertor $1 \mathrm{~s} \sim 4.5 \mathrm{~T}_{\mathrm{e}}$. Sputtered atoms can be Ionized and returned back along the fleld lines to the surface of the $11 \mathrm{miter} /$ divertor near the origin. The charge state of the lons returned to the surface is critical in determining their energy. The charge state of the redeposited impurities was analyzed and found to be $\sim 2-3$ for $10 \mathrm{w}-\mathrm{z}$ materlals and $\sim 4$ for high-Z materials. Therefore, the peak lon energy of 1mpuritles (mostly sputtered atoms returned back) striking the limiter/divertor surface is $\sim 6$ to $9 \mathrm{~T}_{\mathrm{e}}$ for $10 \mathrm{w}-\mathrm{Z}$ and $\sim 12 \mathrm{~T}_{\mathrm{e}}$ for high-Z materials.

The magnitude of erosion by physical sputtering is thus strongly dependent on the plasma edge temperature. Table 1 shows the plasma edge temperature regimes that can minimize hydrogen and self sputtering for low- and high$Z$ materials. Since the self-sputtering yleld for low-Z materials is < 1 at all Ion energles, low-Z materlals are viable at all edge temperature reglmes. However, physical-sputtering erosion is minimized by operating at $T_{e}>1 \mathrm{KeV}$. In addition to the lower hydrogen and self-sputtering yleld, erosion is minimized (perhaps more Importantly) by a reduction in the particle flux at high $T_{e}$ for the same power flux on the limiter/divertor. Medium- and high-Z materials, on the other hand, are viable only below a "threshold" temperature that result in self-sputtering yield of unity. This threshold temperature is $\sim 30$ to $50 \mathrm{eV}$ depending on the specific medium/high-Z materlal.

TABLE 1. PLASMA-EDGE TEMPERATURE ( $\mathrm{T}_{\mathrm{e}}$ ) REGIMES
THAT MINIMIZE PHYSICAL SPUTTERING

\begin{tabular}{|l|c|c|c|}
\hline & $\begin{array}{c}\text { Hydrogen } \\
\text { Sputtering }\end{array}$ & $\begin{array}{c}\text { Self } \\
\text { Sputtering }\end{array}$ & $\begin{array}{l}\text { Attractive } \\
\mathrm{T}_{\mathrm{e}} \text { Regime }\end{array}$ \\
\hline Low-Z Materials & $\mathrm{T}_{\mathrm{e}}<10 \mathrm{eV}$ & $\mathrm{T}_{\mathrm{e}}<30 \mathrm{eV}$ \\
$\mathrm{T}_{\mathrm{e}}>1 \mathrm{keV}$ & $\mathrm{T}_{\mathrm{e}}>1 \mathrm{keV}$ & $\mathrm{T}_{\mathrm{e}}>1 \mathrm{keV}$ \\
Medium- and High-Z Materials & $\mathrm{T}_{\mathrm{e}}<30 \mathrm{eV}$ & $\mathrm{T}_{\mathrm{e}}<40 \mathrm{eV}$ & $\mathrm{T}_{\mathrm{e}}<30 \mathrm{eV}$ \\
\hline
\end{tabular}

In the above discussion (and throughout this paper), we assume that the plasma edge temperature, $T_{e}$, 18 equal to the pre-sheath temperature ( $T_{8}$ ) In front of the surface of the limiter and divertor plate. This is true except for the case of divertor with low $T_{e}(<100 \mathrm{eV})$ where $T_{s} 18$ lower than $T_{e}$ because of cooling in the divertor shannel.

\subsection{Che-teal Sputtering}

Chemical sputtering due to hydrogen and/or oxygen chemical interaction with the plasma-side material was assessed. It is concluded that cheatcal sputtering is unacceptably serious erosion mechanism for graphite. On the 
other hand, oxygen effects on reactive materlals can be benefi:lal in reducing sputtering under some conditions. No serlous chemical sputtering effects could be identified for other materials such as the carbides $\left(\mathrm{B}_{4} \mathrm{C}\right.$, $\mathrm{SIC}$ and TIC).

Chemical sputtering of graphtte by hydrogen ion bombardment for temperatures below $800^{\circ} \mathrm{C}$ has been known for sometime. Methane is formed in the temperature range of $400-800^{\circ} \mathrm{C}$ with a peak at a temperature of 525 to $600^{\circ} \mathrm{C}$. Erosion by hydrogen bombardment above $800^{\circ} \mathrm{C}$ was not known until the recent experiments by Roth, Bohdansky and Wilson. Their results, reproduced in Fig. 3 show that graphite erosion $>1000^{\circ} \mathrm{C}$ increases with temperature with no apparent peak. Helium bombardment does not produce an erosion peak but also exhibits a rapid rise in sputtering above $700^{\circ} \mathrm{C}$. These results indicate a high erosion rate for graphite above $1000^{\circ} \mathrm{C}$ by a mechanism other than physical or chemical sputtering since no hydrocarbon formation was detected at the high temperatures. The erosion rates are large (many centimeters per year) at all temperatures in the range 350 to $1500^{\circ} \mathrm{C}$ at typical INTOR conditions.

\subsection{Plasma Hsruptions}

Erosion of limiter, divertor and first wall surfaces due to the thermal energy dump during plasma disruptions can be significant. Disruptions result in vaporization and, for some materials, a thin melt layer may develop. The stability of the melt layer is a major concern. During a major disruption, the peak energy density at the limiter and divertor plates is 270 and 230 $\mathrm{J} / \mathrm{cm}^{2}$, respectively in the reference INTOR scenario. The peak energy density on the first wall is $\sim 175 \mathrm{~J} / \mathrm{cm}^{2}$ and occurs on the inboard region. During minor disruptions, all the energy goes to the limiter or divertor with a peak of $170 \mathrm{~J} / \mathrm{cm}^{2}$. An extremely severe case for major disruptions in which all the plasma energy goes to the limiter was included in the calculations. This case results in a peak energy density of $535 \mathrm{~J} / \mathrm{cm}^{2}$. The reference time constants for plasma current decay and thermal quench is $20 \mathrm{~ms}$. An alternate case of 5 ms for the thermal quench was considered.

Table 2 shows the thicknesses of vaporized and melted regions per disruptions for candidate materials with 20 and 5 ms thermal-quench time constants. The very high-z materials such as tungsten are more resistant to plasma disruptions. However, these materials experience serious melting at very high peak energy density $\left(>535 \mathrm{~J} / \mathrm{cm}^{2}\right)$ and short time constants ( $\left.5 \mathrm{~ms}\right)$. SiC decomposes rather than melts. Beryllium and stainless steel are the leastresistant to piasma disruptions. They melt at energy densities as low as those corresponding to minor disruptions $\left(170 \mathrm{~J} / \mathrm{cm}^{2}\right)$. The results shown in Table 2 were calculated assuming an initial surface temperature of $300^{\circ} \mathrm{C}$. The actual surface temperature could be substantially higher, and the amount of meterial vaporized and melted is predicted to increase as the initial temperature increases. For example, the melt layer thickness of Be is calculated to Increase from $70 \mu \mathrm{m}$ to $\sim 220 \mu \mathrm{m}$ as the initial surface temperature is increased from 300 to $900^{\circ} \mathrm{C}$ for the reference disruption conditions.

Melt layer stability during disruptions has been analyzed for a variety of conditions. Magnetic forces caused by the interaction of induced currents during the plasma current quench with the magnetic field are considered to be the primary forces which could create an instability. The stability of a beryllium coated 1imiter was evaluated for disruption energy densities of 535 , 
TABLE 2. VAPORIZED AND MELT REGION THICKNESSES, MICRONS PER DISRUPTION (INITIAL TEMPERATURE IS $300^{\circ} \mathrm{C}$ )

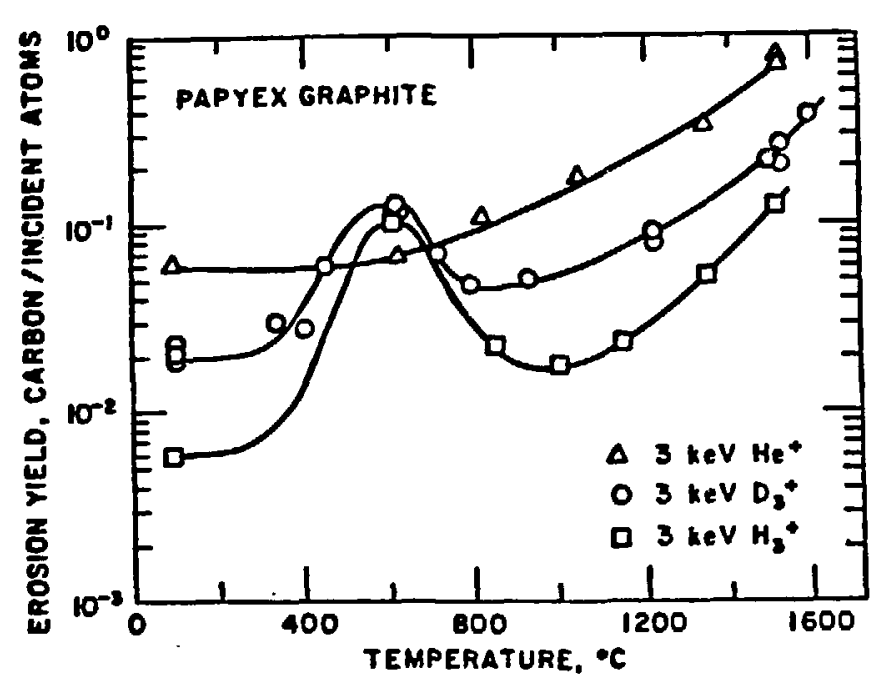

Figure 3. Temperature dependence of the chemical sputtering yield of papyex graphite (from Roth, Bohdansky and Wilson).

\begin{tabular}{|c|c|c|c|c|c|c|c|c|}
\hline & \multicolumn{4}{|c|}{$20=$} & \multicolumn{4}{|c|}{$5=0$} \\
\hline & \multicolumn{2}{|c|}{ Mejor } & \multicolumn{2}{|c|}{ Minor } & \multicolumn{2}{|c|}{ Hefor } & \multicolumn{2}{|c|}{ Minor } \\
\hline & Vapor & Melt & Vapor & Melt & Vapor & Melt & Vapor & Helt \\
\hline F1rgt Hall & \multicolumn{2}{|c|}{$\left(175 \mathrm{~J} / \mathrm{cm}^{2}\right)$} & & & \multicolumn{2}{|c|}{$\left(175 \mathrm{~J} / \mathrm{c}^{2}\right)$} & & \\
\hline Sta1nless Steel & 0 & 7 & & & 0.1 & 60 & & \\
\hline Beryl11um & 0 & $\sin$ & & & 0.2 & 60 & & \\
\hline SIC, IIC & 0 & $\mathbf{M Y}$ & & & 0 & MM & & \\
\hline Divertor, Limiter & \multicolumn{2}{|c|}{$\left(270 \mathrm{~J} / \mathrm{cm}^{2}\right)$} & \multicolumn{2}{|c|}{$\left(170 \mathrm{~J} / \mathrm{cs}^{2}\right)$} & \multicolumn{2}{|c|}{$\left(270 \mathrm{~J} / \mathrm{cm}^{2}\right)$} & \multicolumn{2}{|c|}{$\left(170 \mathrm{~J} / \mathrm{cm}^{2}\right)$} \\
\hline Bery111un & 0.1 & 70 & 0 & MH & 1.1 & 84 & 0.2 & 50 \\
\hline Tungsten & $\mathbf{0}$ & $\mathbf{M}$ & $\mathbf{0}$ & MM & $\mathbf{0}$ & $\mathbf{M}$ & $\mathbf{0}$ & $\mathbf{M}$ \\
\hline Graphite & $<1$ & MI & $<1$ & MM & 1 & MM & $<1$ & MH \\
\hline sic & o & $\mathbf{M}$ & 0 & $\mathbf{M A}$ & 0.1 & $\mathbf{M}$ & 0 & $\mathbf{M}$ \\
\hline THC & $\mathbf{0}$ & My & 0 & $\mathbf{M M}$ & 0.1 & 19 & 0 & NM \\
\hline BeO & 0 & 3 & $\mathbf{0}$ & $\mathbf{M}$ & 5 & 35 & $\mathbf{0}$ & 15 \\
\hline Wmiter (high) & \multicolumn{2}{|c|}{$\left(535 \mathrm{~J} / \mathrm{cm}^{2}\right)$} & & & \multicolumn{2}{|c|}{$\left(533 \mathrm{~J} / \mathrm{cm}^{2}\right)$} & & \\
\hline Berg111un & 2.1 & 155 & 0 & $\mathbf{M}$ & 121 & 14 & 0.2 & so \\
\hline Tungsten & $\mathbf{0}$ & $\mathbf{M}$ & $\mathbf{0}$ & $\mathbf{m}$ & 0.03 & 88 & 0 & $\mathbf{M}$ \\
\hline Graph1te & 1.0 & $\mathbf{M}$ & $<1$ & $\mathbf{N}$ & 7 & $\mathbf{M}$ & $<1$ & $\mathbf{M}$ \\
\hline sic & 0.4 & $\mathbf{M r}$ & 0 & $\mathbf{M M}$ & 19 & $\mathbf{m}$ & 0 & $\mathbf{m}$ \\
\hline TIC & 0.4 & 24 & 0 & $\mathbf{M}$ & 15 & 90 & 0 & $\mathbf{M}$ \\
\hline Beo 0 & 11 & 65 & 0 & NH & 33 & 32 & 0 & 15 \\
\hline
\end{tabular}

M $=$ so selting. 
270, and $175 \mathrm{~J} / \mathrm{cm}^{2}$ and for thermal quench times of 20 and $5 \mathrm{~ms}$. The results indicate that for the reference disruption conditions $\left(270 \mathrm{~J} / \mathrm{cm}^{2}, 20 \mathrm{~ms}\right)$ the melt layer is stable at both the center and the leading edge of the limiter. However, at $535 \mathrm{~J} / \mathrm{cm}^{2}$ for both $20 \mathrm{~ms}$ and $5 \mathrm{~ms}$ disruption times, the melt layer is predicted to be unstable or marginally stable. There still remain considerable uncertainties in the melt layer analysis and additional analytical and experimental work is required.

\subsection{Arcing}

Arcing can potentially be a serious erosion mechanism. Arcing can occur if the magnetic field lines, and hence the plasma, intercepts the surface and the plasma sheath potential exceeds 10-20 V. Since the potential is proportional to $T_{e}$, this condition is most easily met at higher temperatures. In addition, the arc current (1.e., erosion) generally ircreases with $T_{e}$.

Arcing occurs with all materials but a marked reduction is observed for metals with high melting points and for good insulators. A comparison of a number of materlals shows the arcing erosion rates for Mo and $W$ to be the lowest, approximately a factor of 1000 lower than for stainless steel. Erosion of Be is about 5 times that for TiC, both being of the same order of magnitude as stainless steel. BeO and BeC may be better than Be.

Presently known approaches to reducing arcs (e.g., segmentation, conditloning) appear to be ineffective under INTOR conditions. It is concluded that arcing is an important problem and is potentially serious at high plasmaedge temperatures. Therefore, continued studies and experiments are recommended under conditions simulating those of the INTOR reactor environment.

\subsection{Het Brosion/Redeposition Rates}

Detalled calculations of the rates of erosion and the concomitant redeposition were made for the limiter and divertor using both a deterministic methof (REDEP code, USA) and a Monte Carlo method (USSR). A number of candidate plasma-side materials were analyzed for a range of plasma edge temperatures from 20 to $1200 \mathrm{eV}$. Only physical sputtering was considered. This included sputtering by hydrogen (DT) Ions and neutrals, impurities (He) and selfsputtering.

Table 3 shows typical peak net erosion rates for a number of materials at different plasma edge temperatures. The results obtained suggest that erosion and redeposition characteristics at the surfaces of the limiter and divertor plates are qualitatively similar. The major difference is the IImiter leading edge, to be discussed in the following subsection.

The results in Table 3 indicate that net erosion rates for low-Z materials are on the order of (for 50\% avallability factor) $0.8 \mathrm{~cm} / \mathrm{y}$ at plasma edge temperature $\left(T_{e}\right)$ of $20 \mathrm{eV}$ and decreases to $\sim 0.3 \mathrm{~cm} / \mathrm{y}$ at $T_{e}=1200 \mathrm{eV}$. Thus, the net erosion rates for low-Z materials are reasonable $(<1 \mathrm{~cm} / \mathrm{y})$ at all plasma edge temperatures with a significant advantage for $T_{e}>700 \mathrm{eV}$.

High-Z materials (e.g., V, W) result in a very small net erosion rate at plasma edge temperatures below 30-50 eV. The erosion rate for medium-Z materials for $T_{e}<30-50 \mathrm{eV}$ is aignificant but it is lower than that for low $\mathrm{Z}$ 
materials. At higher edge temperatures, medium- and high-z materials are not viable because self-sputtering exceeds unity at ion energies corresponding to $\mathrm{T}_{e}>50 \mathrm{eV}$, as discussed earlier in this section.

It should be noted that the net erosion rate given in Table 3 is the difference between the erosion and redeposition rates, both of which are large as shown in Fig. 4 for beryllium at $T_{e} \Rightarrow 100 \mathrm{eV}$. Therefore, the relative error in estimating the lifetime can be several times larger than the relative error in estimates of the erosion or redeposition rates. Notice also that the bulk properties of a large portion of the tile as well as its surface properties (e.g., physical sputtering) will be controlled by redeposition. There are no data on the properties of redeposited materials under reactor conditions (simultaneous erosion, redeposition, hydrogen and Impurities bombardment, etc.).

\subsection{Liniter Leading Bdge Solutions}

The results shown in Table 3 and Fig. 4 indicate a serlous erosion problem at the limiter leading edge. The erosion rate is several centimeters per year and reduces to $\sim 1 \mathrm{~cm} / \mathrm{y}$ only at $\mathrm{T}_{e}>1000 \mathrm{eV}$.

Two conceptual solutions to the limiter leading edge problem were deve1oped. The first is in-situ regeneration of the limiter low-z coating. This can be accomplished most effectively during reactor operation by infecting a small amount of the low $-Z$ material into the scrapeoff region near the leading edges. Alternatively, techniques for in-situ recoating of the leading edge during reactor shutdown are potentially viable.

A second solution to the leading edge problem has been shown to be viable for plasma edge temperatures $\leq 200 \mathrm{eV}$. Th1s involves the use of dual materials on the limiter. A low-Z coating/cladding is used on the top surface while a high-Z materlal is used at the leading edge. For $T_{e}<200 \mathrm{eV}$, the plasma temperature in the vicinity of the leading edge is $<50 \mathrm{eV}$ where high-z materials are very attractive. The charged-DT sputtering is $\sim 0$. Sputtering by energetic charge exchange neutrals can be significant. However, self-sputterIng 1 s $<1$ at these conditions and the erosion rate of the high-z material remalns small. Furthermore, high-z atoms have a very short ionization meanfree-path $(\sim 0.1 \mathrm{~mm})$ and therefore, the redeposition rate is nearly equal to the erosion rate.

\section{MAXTIUY ALLOHABLE THIGRIESS}

The maximum allowable thickness of the plasma-side tile is one of the two key factors in determining the lifetime of the limiter and divertor plates (the other factor being the net erosion rate by all erosion mechanisms). The maximum allowable thickness was determined by three principal criteria: 1) naximum temperature, 2) maximum allowable stresses, and 3) fatigue. Under the selected INTOR conditions the temperature limit is generally dictated by the maximum in the tile rather than in the heat sink. With the high thermal-conductance attachment, the thickness of the tile can be 11 imited by the stresses and fatigue of the heat sink. Since the surface material is not expected to carry \& primary stress load, no stress limits were applied to the tiles. Cracking of a tile is not considered a fallure as long as it remalns attached to the heat sink. Radiation effects are included indirectly by 1) selecting 
TABLE 3. NET EROSION RATES (REPRESENTATIVE VALUES) $(\mathrm{cm} / \mathrm{y})$ (50\% AVAILABILITY, 80\% DUTY CYCLE)

\begin{tabular}{|c|c|c|}
\hline Plaven zdge Tenperature & $\begin{array}{l}\text { Liniter and } \\
\text { Divertor Surface }\end{array}$ & $\begin{array}{l}\text { Lint ter } \\
\text { Leading Edge }\end{array}$ \\
\hline $\begin{array}{c}\frac{\operatorname{Low}-2 \text { ( Be, } B, C)}{\text { (no chenical puttering) }} \\
20 \mathrm{eV} \\
100 \mathrm{eV} \\
300 \mathrm{eV} \\
700 \mathrm{eV} \\
1200 \mathrm{eV}\end{array}$ & $\begin{array}{l}0.8 \\
0.7 \\
0.6 \\
0.4 \\
0.3\end{array}$ & $\begin{array}{c}4 \\
15 \\
8 \\
3 \\
1\end{array}$ \\
\hline $\begin{array}{l}\underline{s \pm C} \\
\quad 50 \mathrm{et} \\
>50 \mathrm{eV}\end{array}$ & 0.5 & $\begin{array}{l}6 \\
?\end{array}$ \\
\hline 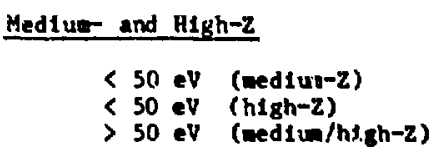 & $\begin{array}{c}<1 \\
\sim 0 \\
\text { not viable }\end{array}$ & $\begin{array}{c}- \\
\sim 0 \\
\text { not viable }\end{array}$ \\
\hline
\end{tabular}

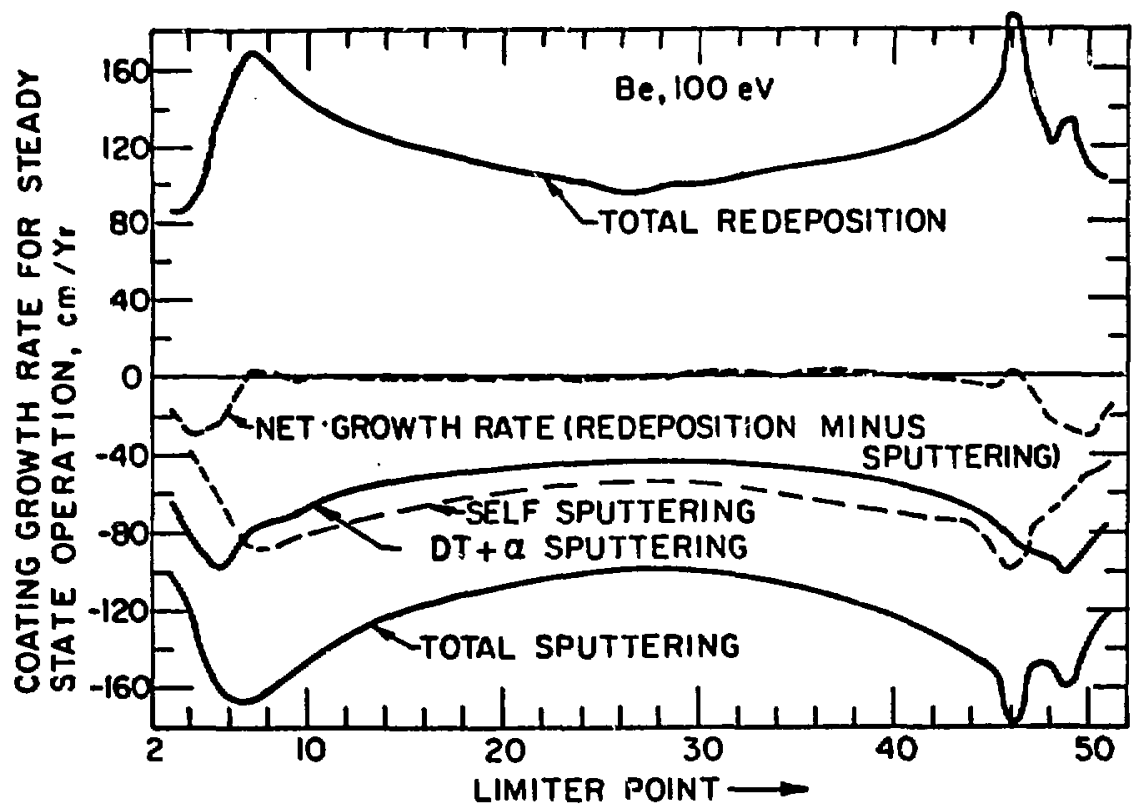

Figure 4. Erosion (physical sputtering only) and redeposition rates for beryllium as a function of spatial points at the limiter surface for a plasma-edge temperature of $100 \mathrm{eV}$. 
temperature limits that avold excessive bulk radiation damage (e.g., swe1ling), and by 2) accounting for radiation effects on the thermophysical properties, (e.g., reduction in the thermal conductivity).

Figure 5 shows the maximum temperature at the $11 \mathrm{miter}$ or divertor plate tiles as a function of the tile thickness at the top surface. The peak heat flux is $2.4 \mathrm{MW} / \mathrm{m}^{2}$, and perfect thermal contact with a $0.15 \mathrm{~cm}$ thick copper substrate is assumed. Beryllium and tungsten result in much lower temperature than 1rradiated graphite, TIC and conventional S1C. The rapid reduction in the thermal conductivity of BeO with temperature causes Beo tiles to have much higher temprature than beryllium for tile thicknesses $>1 \mathrm{~cm}$. The masimum temperature of the copper heat sink is generally $\sim 150^{\circ} \mathrm{C}$ with a modest decrease for those cases where the tile temperature is high enough for significant radiative heat transfer to occur at the plasma side. The maximum temperature in a vanadium heat sink is $\sim 250^{\circ} \mathrm{C}$. Therefore, the maximun tile temperatures with a vanadium heat sink are $\sim 100^{\circ} \mathrm{C}$ higher than those in Fig. 5 .

The tile temperatures at the leading edge with a peak heat flux of ! $\mathrm{MW} / \mathrm{m}^{2}$ are always lower than those at the top surface (peak heat flux of 2.4 $\mathrm{MW} / \mathrm{m}^{2}$ ). In contrast, the maximum temperature of the heat sink $1 \mathrm{~s}$ generally higher at the leading edge than at the top surface. The maximum heat sink temperature at the leading edge increases significantly with tile thickness but it remains $<200^{\circ} \mathrm{C}$ for $\mathrm{Cu}$ and $<350^{\circ} \mathrm{C}$ for vanadium for a tile thickness< $3 \mathrm{~cm}$.

Stress and fatigue analyses were carrled out for a number of heat sink and tile materials. The stresses within the heat sink depend upon the constraint imposed by the coating or tiles. If one assumes that the constraint of the tile is minimal, then the stresses are more severe at the leading edge than at the top surface because of the addirional geometric constrainte at the leading edge. On the other hand, if the tile constraints are included, then the stresses at the top surface are more severe than at the leading edge. For the case of tiles whose width to thickness ratio $1 \mathrm{~s}$ large, the $3 \mathrm{~S}_{\mathrm{m}}$ stress criteria is exceeded at tile thicknesses between 1 and $2 \mathrm{~cm}$. If the tile width is only $2 \mathrm{~cm}$, then the effectlve tile thickness acting to constrain the substrate is reduced, and the $3 S_{m}$ stress criteria is not exceeded.

The stress/fatigue analysis shows that annealed tough pitch copper, because of its inferior fatigue properties cannot meet the 11 fe requirement for any reasonable thickness of coating. Vanadium on the other hand, can meet the life requirement with a tile thickness of up to $\sim 2 \mathrm{~cm}$ for Be or Be0, $\sim 1.5 \mathrm{~cm}$ for SIC and $\sim 1 \mathrm{~cm}$ for $W$. A copper alloy such as Cu-2\% Be has significnatly better fatigue propertles than annealed copper because of 1 ts higher strength and may prove acceptable.

Table 4 shows the maximum allowable thickness of the tile for a number of candidate materials. For the divertor plate and limitei top surface, the constraint of the tile on the heat sink 18 ignored and thickness is limited by the maximum temperatures indicated in the table. The allowable thickness of the leading edge is limited by a $10^{5}$ cycles fatigue life $(\sim 2$ y) criterion in a vanadium heat sink. No advantage was taken of the fact that continued erosion of the tiles will increase the fatigue $11 \mathrm{fe}$. 


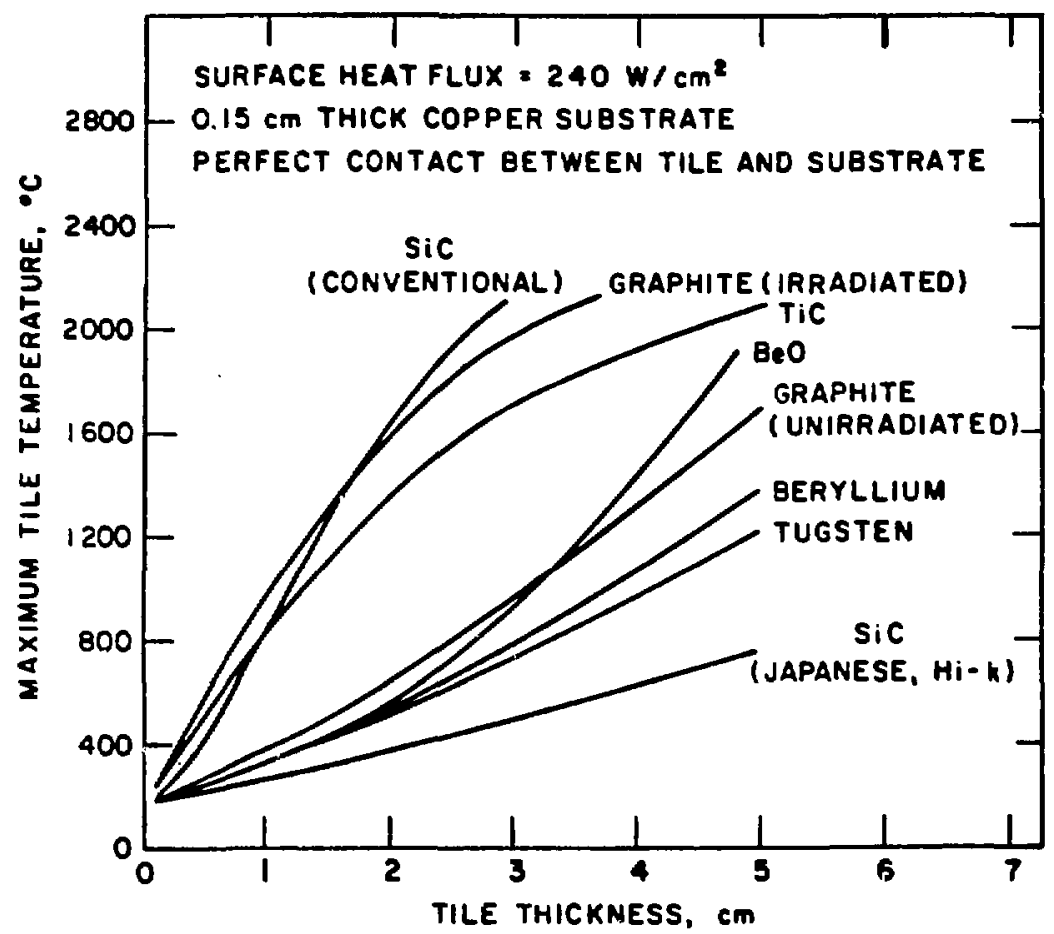

Figure 5. Maximum tile temperature vs. thickness for various tile materials at the top surface of limiter/divertor with perfect contact between the tile and copper heat sink.

TABLE 4. MAXIMUM ALLOWABLE THICKNESS OF PLASMA-SIDE MATERIALS

\begin{tabular}{|c|c|c|c|}
\hline \multirow[b]{2}{*}{ Surface Material } & \multicolumn{2}{|c|}{ Divertor, Walter Top } & \multirow{2}{*}{$\begin{array}{c}\text { Lint ter Edge } \\
\begin{array}{c}\text { Allowable } \\
\text { Th1ckmese } \\
\text { (cn) }\end{array}\end{array}$} \\
\hline & $\begin{array}{l}\text { Temperature } \\
\text { Lintt } \\
\text { ('C) }\end{array}$ & $\begin{array}{l}\text { Allowable } \\
\text { Th1ckneas } \\
\text { (ca) }\end{array}$ & \\
\hline Be & 700 & 2.5 & 2.1 \\
\hline c & 500 & 0.4 & - \\
\hline Beo & $\begin{array}{l}>600 \\
<1800\end{array}$ & 2.4 & 2.2 \\
\hline Sic (low-R) & 1200 & 1.0 & 1.7 \\
\hline S1C (h1gh-k) & 1200 & $(1.0)$ & (1.7) \\
\hline H. Ta & 600 & 3.0 & 0.9 \\
\hline
\end{tabular}

- Peak heat flux $-2.4 \mathrm{~m} / \mathrm{m}^{2}$ (tenperature $11 \mathrm{n} 1 \mathrm{ced}$ ).

b Peak heat flux $-1 \mathrm{~m} / \mathrm{m}^{2}$ (fatigue lielted, $\nabla$ heat alnk).

abeffect of Irradiation on thereal conductivity is eccounted for. 
Beryllium of fers the largest allowable thickness $(2.5 \mathrm{~cm})$. The allowable graphite thickness is severely 1 imited by a low maximum temperature of $500^{\circ} \mathrm{C}$ to avoid excessive chemical sputtering and by the reduction in thermal conductivity under Irradiation. The advantage of the high thermal conductivity SiC suggested by the Japanese delegation could be lost due to irradiation effects. The allowable thickness at the leading edge 18 generally lower than at the top surface with the largest reduction for $W$ and $\mathrm{Ta}$.

\section{LIFETIE ANALSIS}

Detalled analysis of lifetime was carried out using estimates of net erosion rates and maximum allowable thicknesses as summarized in the preceding sections. Table 5 is a summary of the lifetime analysig for several tile materlals at the divertor plate and limiter top surfaces. The results given in the table are for a V-15Cr-5TI heat sink and for stage III, 1.e., 50\% avallability. Lifetime estimates are shown for the case with no disruptions and for two disruption conditions with the assumption that all the melt layer erodes. The two disruption conditions are for: 1) the reference case with 20 ms time constant and peak energy density of $270 \mathrm{~J} / \mathrm{cm}^{2}$ for major disrupt lons and $170 \mathrm{~J} / \mathrm{cm}^{2}$ for minor disruptions, and 2) the worst case with 5 ms and 535 $\mathrm{J} / \mathrm{cm}^{2}$ for major and $170 \mathrm{~J} / \mathrm{cm}^{2}$ for minor disruptions. For low-Z materials (Be, $\mathrm{BeO}$ and $\mathrm{C}$ ) the 11 fetime is given at two plasma edge temperatures ( $\mathrm{T}_{\mathrm{e}}$ ) of 100 and $700 \mathrm{ev}$. The 1 ifetime for unirradiated BeO and $\mathrm{C}$ are shown for comparison purposes only since the reduction in thermal conductivity occurs after $\sim 1$ dpa irradiation ( 1 month of operation). The calculated lifetimes for Be and BeO include the effect of initial surface temperature on the disruption losses.

For the two cases of no disruptions and all melt layer erosion under the reference disruption conditions ( $20 \mathrm{~ms}$ time constant), the lifetime of beryllium is genera?'y longer than that of Irradlated $C$ and BeO. Beryllium suffers the largest reduction in 1 ffe by melt layer erosion because it is the least disruption-resistant. For the worst disruption cases $\left(535 \mathrm{~J} / \mathrm{cm}^{2}\right.$ and $5 \mathrm{~ms}$ major disruptions), the lifetime of beryllium is reduced to $\sim 0.6$ years conpared to $\sim 2$ years under the reference disruption conditions.

The 11 fetimes for SIC, $W$ and Ta are shown in Table 5 only for a plasma edge temperature of $50 \mathrm{eV}$. At $T_{e}=50 \mathrm{eV}$ the lifetime of SIC is $\sim 2.5$ years for the reference disruption conditions and 1 s reduced to $\sim 1.9$ year under the worst disruption case. For $\mathrm{T}_{e}>50 \mathrm{eV}$, the viability of Sic is not clear due to uncertainties in self-sputtering discussed earlier. For $T_{e}<50 \mathrm{eV}$, the lifetime of high-Z materials such as $W$ and $T a$ is not limited by sputtering erosion and can be very long. Ta and $W$ are also very resistant to plasma disruptions and they offer the longest life of al1 waicerials examined even under the worst disruption conditions. However, at $T_{e}>50 \mathrm{eV}$, these high- $\mathrm{Z}$ materials are not viable because of the self-sputtering problems discussed earlier.

The lifetime of the limiter leading edge is substantially shorter than that at the top surface if no special design measures are taken. For example, the lifetime of a beryllium leading edge $1 \mathrm{~s} \sim 0.1 \mathrm{y}$ at $100 \mathrm{eV}$ and $0.9 \mathrm{y}$ at 700 eV Ignoring disruption effects. However, the two leading edge solutions described (use of high-Z leading edge with $\mathrm{T}_{e}<200 \mathrm{eV}$ and $1 \mathrm{n}-\mathrm{situ}$ recoating at all $\mathrm{T}_{\mathrm{e}}{ }^{\mathrm{s}} \mathrm{s}$ ) permit the lifetime of the leading edge to be considerably longer than that at the top surface. 
TABLE 5. LIFETIME (YEARS) DURING STAGE III (50\% AVAILABILITY) FOR DIVERTOR/LIMITER TOP SURFACE (V-15Cr-5Ti HEAT SINK)

\begin{tabular}{|c|c|c|c|c|c|c|}
\hline \multirow{3}{*}{$\begin{array}{l}\text { Major Disrupt. Conditions } \\
\text { P1asma Edge Temperature }\end{array}$} & \multicolumn{2}{|c|}{ No Disruptions } & \multicolumn{4}{|c|}{ With Disrupt Ions (A11 Melt Layer Erodes) } \\
\hline & & & \multicolumn{2}{|c|}{$\left(270 \mathrm{~J} / \mathrm{cm}^{2}, 20 \mathrm{~ms}\right)$} & \multicolumn{2}{|c|}{$\left(535 \mathrm{~J} / \mathrm{cm}^{2}, 5 \mathrm{~ms}\right)$} \\
\hline & $100 \mathrm{eV}$ & $700 \mathrm{eV}$ & $100 \mathrm{eV}$ & $700 \mathrm{eV}$ & $100 \mathrm{eV}$ & $700 \mathrm{ev}$ \\
\hline Be & 3.8 & 6.3 & 1.8 & 2.2 & 0.6 & 0.6 \\
\hline BeO (Irradiated) & 2.2 & 5.4 & 1.3 & 1.8 & 0.9 & 1.2 \\
\hline Beo (unirradiated) & 4.1 & 10.1 & 2.1 & 3.4 & 1.7 & 2.2 \\
\hline C (Irradiated) & 0.7 & 0.8 & 0.7 & 0.8 & 0.5 & 0.6 \\
\hline SIC $^{*}$ (Irradiated) & 2.5 & 0 & 2.5 & 0 & 1.9 & 0 \\
\hline SiC ${ }^{*}$ (unirradiated) & 3.4 & 0 & 3.4 & 0 & 2.7 & 0 \\
\hline$w^{*}$ & L & 0 & $\mathrm{~L}$ & 0 & 4.8 & 0 \\
\hline $\mathrm{Ta}^{*}$ & L & 0 & $\mathbf{L}$ & 0 & $\sim 4$ & 0 \\
\hline
\end{tabular}

*At plasma edge temperature $\left(T_{e}\right.$ ) of $50 \mathrm{eV}$. Lifetime is extremely short (because of self sputtering $>$ 1) for these materials at $\mathrm{T}_{e}>50 \mathrm{eV}$.

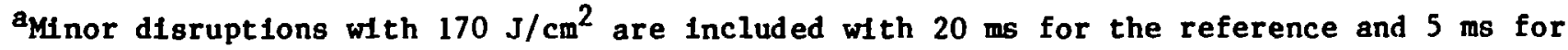
the worst case.

Long life predicted (11fe is not erosion 1imited). 


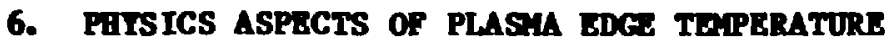

Resulcs from the previous section Indicate that the choice of materials for and the lifetime of the limiter and divertor plate surface are strongly dependent on the pre-sheath temperature $\left(T_{s}\right)$ of the plasma in front of the surface. For the limiter, $T_{s}$ is the same as the plasma edge temperature, whereas for the divertor plate $T_{s}$ is less than $T_{e}$ if $T_{e}$ is low ( $\left.<100 \mathrm{eV}\right)$ because of cooling in the divertor channel.

Plasma transport calculations have been performed to evaluate the probable values of $T_{e}$ and $T_{s}$. With edge refueling and without high edge radiation, it is est Imated that the most probable edge temperature is in the range $\sim 100$ $<\mathrm{T}_{\mathrm{e}}<\sim 300 \mathrm{eV}$. Special methods for achieving the more desirable high and low edge temperatures reglons were investigated.

Transport codes were used to study the production of high edge temperatures by using pellet injection. For these studies the fraction of the recycled plasma pumped by the limicer system was reinjected into the discharge in the form of $1 \mathrm{~mm}$ diameter pellets. This reduced the recycling and Increased the edge temperature. For a realistic upper limit to the pumping fraction of about 5\%, temperatures in the $700-800 \mathrm{eV}$ range were obtained when fmpurity radiation was neglected. Increased pumping (1.e., 20\%) produced temperatures in the $1 \mathrm{KeV}$ range, but this pumping level is not realistic. The conclusion Is that although temperatures above $700 \mathrm{eV}$ can be obtained in modelling studies, it would be Imprudent to base the INTOR design on obtaining these temperatures. This conclusion 1s, in part, based on the high probability that impurity radiation will reduce the temperature by an unacceptable amount.

The potential realization of edge temperature below $50 \mathrm{eV}$ in the presence of high edge radiation was studled. These conditions were obtalned in transport code studies where the impurity transport was assumed to be governed by neoclassical diffusion superimposed on an empirical transport at the hydrogen rate. Under these conditions the impurities (e.g., iron) peaked at the edge, and a low temperature edge was obtained with acceptable central radiation. However, this same model, applied to ISX discharges, produced the same edge peaking in impurity concentration, a condition not observed experimentally. The conclusion is that there is significant risk involved in basing the INTOR collector plate or limiter design on obtaining edge temperatures below $50 \mathrm{eV}$ because of uncertainties in the impurity behavior near the edge.

The possibility of achieving $T_{s}<T_{e}$ in the pololdal divertor was investigated. The INTOR pololdal field divertor was modelled taking into account the finite parallel electron thermal conduction. The high recycling of neutrals at the divertor plate was found to produce substantial increases in plasma density near the plate and significant cooling in this reglon. An additional reduction in overall edge temperature results from an increase in total edge density with divertor operation. Conditions were obtained with electron temperatures as $10 \mathrm{w}$ as $25 \mathrm{eV}$ at the plasma sheath. Taking into account uncertainties in the edge conditions, this 1 s probably a lower $11 \mathrm{mit}$ on the temperature at the sheath. However, the sheath temperature at the divertor plate should certainly be significantly less than the sheath temperature at the limiter, for comparable plasma edge conditions. If the plasma edge temperature is sufficiently low that $T_{s}<50 \mathrm{eV}$ at the divertor collector plate, then a high-Z surface can be used and the erosion would be quite small. 


\subsection{CONCLOSIONS AND RECONETDATIONS}

1. Impurity control remains a major issue in the design of tokamak reactors. The two leading candidates, a pololdal divertor and a pump limiter, each have considerable uncertainties. The divertor appears to have advantages in impurity control and helium pumping but adds considerable mechanical and magnetic complexity to the reactor. Uncertainties in the scrapeoff conditions, erosion by physical sputtering, disruptions and arcing, and in redeposition of eroded materials make prediction of the lifetime of the limiter and divertor plate very difficult.

2. A polofdal divertor design has been developed for INTOR. Analysis shows that it will provide adequate control of Impurities and acceptable hellumremoval capability. The overall magnetics design is acceptable but additional analysis is required to establish the specific characteristics of the separatrix control colls. Angling of the divertor plates relative to the field lines is necessary to reduce the peak heat flux to $\sim 2-3 \mathrm{MW} / \mathrm{m}^{2}$.

3. A pumped limiter design has been developed for INTOR. Two-channel pumping and shaping of the limiter are necessary to achieve adequate pumping while maintaining the peak heat flux to $\sim 2-3 \mathrm{MW} / \mathrm{m}^{2}$ on the surface and $\sim 1-2$ $\mathrm{MW} / \mathrm{m}^{2}$ at the leading edges. Peak heat fluxes are sensitive to plasma edge conditions and plasma position.

4. The evaluation of three plasma edge temperature regimes resulted in the following conclusions:

A. Edge temperatures above $700 \mathrm{eV}$ reduce erosion of low-Z materials. Temperatures above $700 \mathrm{eV}$ could be realized by reducing the edge density with pellet injection and high pumping efficlency. However, the INTOR participants judge that the realization of the high-edge temperature condition is sufficlently uncertain that it would be imprudent to base the design on this condition.

B. The mediun edge temperature $\left(100 \mathrm{eV}<\mathrm{T}_{\mathrm{e}}<400 \mathrm{eV}\right)$ can be easily obtained. However, erosion is very severe. Achleving a reasonable 11 fetime for the 1 imiter and divertor plate requires experimental veriflcation of the prediction that most of the eroded materials will be redeposited and that the properties of the redeposited material are acceptable.

C. Low-edge temperatures ( $<50 \mathrm{eV})$ could be obtained with high-edge radiation. However, the physcis feasibility of attaining the low-edge temperature conditions remains to be established experimentally. Limiter and divertor plate lifetimes can be relatively long if disruption-resistant high-Z materials are used.

5. The selection of reference materials for the high heat flux components depends on a number of criterla which are almed at maximizing the component lifetime. In particular, the selection of the plasma-side materials depends strongly on the plasma edge conditions and the charge state of impurity lons striking the limiter. The charge state is estimated to be 2-3 for low-Z materials and $\sim$ 3-4 for high-Z materials. The plasma side materials considered are $\mathrm{H}, \mathrm{Ta}, \mathrm{Be}, \mathrm{BeO}, \mathrm{C}, \mathrm{SIC}$, and TiC. For a plasna- 
edge temperature $<50 \mathrm{eV}$ (Ion energies $<400-700 \mathrm{eV}$ ), high-z materials such as tungsten or tantalum are viable and preferrable because of low erosion and good resistance to disruptions. Tantalum is the preferred high-Z material because its fabrication properties are superior to those of tungsten. At Ion energies $\geq 400-700 \mathrm{eV}$, the self-sputtering coefficlent of all medium- and high- $\mathrm{z}^{2}$ materials exceeds unity, and therefore a runaway sputtering cascade ts predicted. Thus, at a plasma-edge temperature $>50 \mathrm{eV}$ only low $\mathrm{Z}$ materials (C, $\mathrm{B}, \mathrm{Be}, \mathrm{B}_{4} \mathrm{C}$, BeO) are viable since their sputtering yield never exceeds unity. Beryllium is the preferred low- $Z$ material primarily because the other low $Z$ materials have serious flaws in at least one area. SIC and TiC have self-sputtering coefficlents which may exceed unity. Graphite exhibits high chemical sputtering rates, and $\mathrm{BeO}$ (along with other refractory compounds like SiC) is predicted to have its thermal conductivity reduced substantially by neutron radiation. The major concern with beryllium is the stability of the melt layer formed under disruptions. Two classes of alloys, copper alloys and vanadium alloys, have been considered as heat sink materials.

6. Erosior by physical sputtering $1 \mathrm{~s}$ predicted to be mitigated by redeposition of sputtered particles. In the case of $11 \mathrm{miters,}$ where there is a concern about the buildup of sputtered impurities in the plasma, redeposition is predicted to occur at a level such that the impurity buildup is acceptably low. Sputtering of most of the first wall is expected to be low because the charge exchange particle flux is predicted to be concentrated only in the vicinity of the limiter or divertor plates. The first wali in the vicinity of the impurity control componenes needs to be protected from the charge exchange flux, however.

7. The basic design configuration of the 11miter and divertor collector plate consists of a water cooled heat sink composed of a high thermal conductivity structural material upon which is attached a surface material that is directly exposed to the plasma. Such a duplex structure is required because in almost all cases, materials that meet the sputtering requirements do not have the mechanical properties required for structural support. The preferred attachment concept is a high strength, high thermal conductance bond.

8. The detailed design of the impurity control components is dependent on the plasma edge conditions. There are three different designs corresponding to the three edge temperature regimes considered. At low plasma edge temperatures, tantalum or tungsten are preferred for the limiter and divertor, for the reasons stated above. Austenitic stainless steel can be employed as the heat sink material in spite of its poor thermophysical properties because the heat flux to the limiter is low. At medium edge temperatures, for both the limiter and divertor, beryllium is used as the plasma side material, and efther a vanadium or copper alloy is used for the heat sink material. At the limiter leading edge, where particle energies are $\leq 700 \mathrm{eV}$, tantalum is used to reduce the sputtering erosion. At high edge temperatures, the limiter design is similar to the medium edge temperature design except beryllium is used at the leading edges as well because of concern for self sputtering at the high particle energies.

9. Stress and fatigue analyses indicate that the maximum allowable thickness of the plasma side material is sensitive to the constraint imposed by the 
material on the heat sink. The stresses can be alleviated by reducing the width of the plasma side tiles, which reduces the effective thickness, or by introducing a compliant layer, consisting of a sintered metal fiber structure of low density, between the heat sink and plasma side material. Initial analysis of a structure with a high strength bond indicates that a tile width of only $\sim 2 \mathrm{~cm}$ is required to reduce the thermal fatigue stress range to an acceptable level. A compliant layer allows the heat sink and surface material to expand almost independently of each other during heatIng, but the low thermal conductance of the compliant layer results in higher temperatures in the surface material. The higher temperatures could eliminate the use of low melting point materials such as Be. Additional theoretical and experimental work is required to determine the most appropriate way of controlling stresses in duplex structures.

10. The lifetime of high heat flux components is dependent on the maximum allowable thickness for the plasma side material and the material loss rate due to physical sputtering and disruption vaporization and melting. The predicted lifetimes vary with the plasma edge conditions and the selected plasma side materlal. In the case of the low edge temperature, the est1mated lifetime for a tantalum coated component is the ilfetime of the reactor because of the negliglble material 108s. In the case of the medium and high edge temperatures, the predicted 1ifetime of beryllium coated components is $\sim 2 \mathrm{y}$ at $50 \%$ reactor avallability and at the reference disruption conditions. The lifetimes can be quite sensitive to the assumed disruption conditions. Because of the uncertainties in the frequency, decay time constants, and energy deposition of disruptions, the predicted iffetime for beryllium can vary by a factor of 5 . In addition, it is not known at this time what fraction of a melt layer formed during a disruption is lost from the surface. Additional theoretical and experimental effort is needed. 
1. "International Tokamak Reactor - Phase 2A," International Atomic Energy Agency, Vienna (to be published).

2. R. J. Verbeek, et al., "Critical Issues," European Contribution to the INTOR-Phase IIA Wrokshop, Vlenna, Austria, IAEA, EUR FU BRU/XII-132/82/ EDV30 (1982).

3. N. Fujisawa, et al., "Critical Issues," Japanese Contribution to the International Tokamak Reactor, Phase-2A Workshop, Vienna, Austria, IAEA (1982).

4. W. M. Stacey, Jr., et al., "Critical Issues," U.S. FED-INTOR Activity and The U.S. Contribution to the International Tokamak Reactor, Phase-2A Workshop, Vienna, Austria, IAEA, USA FED-INTOR/82-1 (1982).

5. B. B. Kadontsev, et al., "Critical Issues," USSR Contribution to the Phase IIA of the INTOR Workshop, Vienna, Austria, IAEA (1982). 


\section{Distribution for ANL/FPP/MM-173}

\section{Internal:}

M. Abdou

C. Baker

E. Beckjord

C. Boley

J. Brooks

F. Cafasso

Y. Cha

R. Clemmer

D. Ehst

K. Evans

P. Finn

B. Frost

Y. Gohar

L. Greenwood

D. Gruen
A. Hassanein

C. Johnson

J. Jung

M. Kaminsky

S. Kim

Y-K. Kim

R. Kustom

R. Lar1

B. Loomis

Y. Liu

S. Majumdar

V. Maroni

R. Mattas

B. Misra

L. NeImark
F. Nichols

J. Norem

R. Nygren

W. Praeg

J. Rest

J. Roberts

D. Smith

H. Stevens

L. Turner

R. Weeks

ANL Patent Dept.

FP Program (50)

ANL Contract File

ANL Libraries (2)

TIS Files (6)

\section{External:}

DOE-TIC, for distribution per UC-20 :108)

Manager, Chicago Operations office, DOE

Special Committee for the Fusion Program:

S. Baron, Burns \& Roe, Inc., Oradell, N.J.

H. K. Forsen, Exxon Nuclear Co., Inc., Bellevue, Wash.

M. J. Lubin, Standard 011 Co. of Ohio, Warrensville Heights, OH

G. H. Miley, U. of Illinols, Urbana, IL

P. J. Reardon, Princeton University

D. Steiner, Rensselaer Polytechnic Inst.

i. R. Symon, U. of Wisconsin-Madison

K. Thomassen, Lawrence Livermore National Lab.

Director, Science Applications, Inc.

R. Aamodt, Sclence Applications, Inc.

D. Alger, Untversity of Missouri

R. Alsmiller, Oak Ridge National Laboratory

D. Anthony, General Electric Co.

W. Argersinger, Jr., University of Kansas

R. Axtmann, Princeton University

R. Balzheizer, Electric Power Research Institute

D. Beard, DOE/Office of Fusion Energy

S. Berk, DOE/Office of Fusion Energy

W. Berry, Untversity of Notre Dame

C. Blattner, McDonnell Dougles Astronautics Company

S. L. Bogart, Science Applications, Inc.

D. Bruggink, University of Wisconsin

S. Buchsbaun, Bell Telephone Laboratories, Inc.

T. Burch, Marquette University

S. Burnett, GA Technologies

E. Burrel1, Loyola University of Chicago

J. Butterworth, Culham Laboratory, UNITED KINGDOM 
J. Cantlan, Michigan State University

G. Casini, Joint Research Centre, ITALY

R. Challender, United Kingdom Atomic Energy Authority, UNITED KINGDOM

$\mathrm{C}-\mathrm{H}$. Chen, Institute of Plasma Physics, PEOPLE'S REPUBLIC OF CHINA

F. Chen, University of California

M-S. Chen, Institute of Plasma Physics, PEOPLE'S REPUBLIC OF CHINA

L-T. Chiu, Institute of Plasma Physics, PEOPLE'S REPUBLIC OF CHINA

J. Clark, Washington University

C. Coberly, University of Wisconsin

T. Coffey, Naval Research Laboratory

R. Coffman, University of Iowa

S. Cohen, Princeton University

N. Cohn, Ohio Untversity

S. Cooper, University of Wisconsin

J. Corbally, Jr., University of Illinols

B. A. Cramer, Gak Ridge National Laboratory, FEDC

R. Cutkosky, Carnegie-Mellon University

R. Davidson, MIT Plasma Fusion Center

N. A. Davies, DOE/Office of Fusion Energy

J. Decker, DOE/Offlce of Fusion Energy

W. Dove, DOE/Office of Fuston Energy

H. Dreicer, Los Alamos National Laboratory

W. Drummond, University of Texas at Austin

A. Dupas, Centre for Nuclear Studies, FRANCE

W. Elilis, DOE/Office of Fusion Energy

R. Endicott, Public Service Electric and Gas Research Corporation

J. Felnstein, Varian Associates, Inc.

C. Finfgeld, DOE/Office of Fusion Energy

C. A. Flanagan, Oak Ridge National Laboratory, FEDC

J. Foster, Jr., TRW, Inc.

T. K. Fowler, Lawrence LIvermore National Laboratory

G. M. Fuller, Oak Ridge National Laboratory, FEDC

H. Furth, Princeton University

R. Galvas, Unversidade Estabual de Campinas, BRAZIL

J. Gammel, St. Louis Universicy

F. Garner, Hanford Englneering Development Laboratory

K. Gentle, University of Texas at Austin

$\mathrm{J}$ Gilligan, University of Illinols

R. E. Gold, Westinghouse Electric Corporation

E. Goldwasser, University of I111nols

J. Gordon, TRW, Inc.

M. Gottlieb, Princeton University

H. Grad, New York University

S. Gralnick, Grumman Aerospace Corporation

D. Graunann, GA Technologies

E. Greenspan, NRCN, ISRAEL

B. Gruber, Southern Illinols University

R. Guenther, Batelle-Pacific Northwest Laboratory

J. R. Halnes, Oak Ridge Natlonal Laboratory, FEDC

R. Hancox, Culham Laboratory, UNITED KINGDOM

A. Haught, Untted Technologles Research Center

I. Hedrick, Grumman Aerospace Corporation

N. Hershkowitz, University of Iowa

G. Hess, DOE/Office of Fusion Energy 
G. Higgins, Illinols Institute of Technology

T. Hiraoka, JAERI

R. Hirsch, Exxon Research and Engineering Company

H. Horwitz, General Electric Company

B. L. Hunter, Oak Ridge National Laboratory, FEDC

R. Huse, Public Service Electric and Gas Company

A. Husseiny, Iowa State University

D. Ignat, Princeton University

R. Impara, DOE/Office of Fusion Energy

T. Jernigan, Oak Ridge National Laboratory

R. Johnson, General Dynamics - Convair

J. Kallfelz, Georgia Institute of Technology

J. Kalnavarns, MPB Technologies, Inc., CANADA

T. Kammash, University of Michigan

J. Killeen, Lawrence Livermore National Laboratory

K. Kite, Nuclear Assurance Corporation

D. Klein, Westinghouse Electric Corporation

I. Knobloch, Max Planck Inst. fur Plasmaphysik, FEDERAL REPUBLIC OF GERMANY

H. Koffler, University of Minnesota

J. Kokoszenski, Ralph M. Parsons Company

A. Kolb, Maxwell Laboratorles

H. Kouts, Brookhaven National Laboratory

G. Kulcinski, University of Wisconsin

W. Kunkel, University of California

R. Langley, Sandia Laboratories

T. Latham, United Technologies Research Center

D. Leger, CEN-Saclay, Service DCAEA/SECF., FRANCE

R. Lengye, Max Planck Institut fur Plasmaphysik, WEST GERMANY

$C-s$. LA, Institute of Plasma Physics, PEOPLE'S REPUBLIC OF CHINA

C. Y. Li, Cornell University

M-T. LH, Institute of Plasma Physics, PEOPLE'S REPUBLIC OF CHINA

L. Lidsky, Massachusetts Institute of Technology

F. Loeffler, Purdue University

R. Lofgren, University of California

M. Lubell, Oak Ridge National Laboratory

B. Ma, Iowa State University

P. Maziasz, Dak Ridge National Laboratory

R. Meyerand, United Technologies Research Center

D. Miller, Indiana University

R. Mills, Princeton University

J. Mingle, Kansas State University

D. Mintzer, Northwestern University

G. D. Morgan, McDonnell Douglas Astronautics Company

0. Morgan, Oak Ridge National Laborat)ry

G. Moses, Untversity of Wisconsin

L. Muhlestein, Hanford Engineering Development Laboratory

T. Naicakita, Toshiba Corporation, JAPAN

S. Naymark, Nuclear Services Corporation

D. Nelson, DOE/Office of Fusion Energy

W. D. Nelson, Oak Ridge National Laboratory, FEDC

G. Odette, University of California, Santa Barbara

T. Ohkawa, GA Technologies

E. Oktay, DOE/Office of Fusion Energy

J. Osher, Lawrence Livermore National Laboratory 
C. Overberger, University of Michigan

N. Palladino, Pennsylvanta State University

R. Post, Lawrence LIvermore National Laboratory

M. Prelas, UnIversity of Missour1-Columb1a

R. Price, DOE/Office of Fusion Energy

J. Purcel1, GA Technologles

R. Pyle, Untversity of California

J. Raeder, Max Planck Institute of Plasmaphysik, FEDERAL REPUBLIC Or GERMANY

M. Ragheb University of Illinois

R. Redmond, Oh1o State University

H. Reilly, EG\&G Idaho, Inc.

M. Ricketts, Cul ham Laboratory, UNITED KINGDOM

M. Roberts, DOE/Office of Fusion Energy

A. Robson, Naval Research Laboratory

J. Rogers, Los Alamos National Laboratory

D. Rose, Massachusetts Institute of Technology

P. Rose, Nova Assoclates, Inc.

M. Rosenbluth, Institute for Advanced Study

M. Rosenthal, Oak R1dge National Laboratory

J. Roth, Orlando, Florida

R. Santoro, Oak Ridge National Laboratory

M. Sawan, UnIversity of Wisconsin

G. Sawyer, Los Alamos National Laboratory

P. Schiller, Jolnt Research Centre, Ispra Establishment, ITALY

K. Schm1tter, Max Planck. Inst. fur Plasmsphys1k, FEDERAL REPUBLIC OF GERMANY

D. Schuele, Case Western Reserve University

K. Schultz, GA Technologles

R. Seale, University of Artzona

T. E. Shannon, Oak Ridge National Laboratory, FEDC

G. Shatalov, I. V. Kurchatov Institute of Atomic Energy, Moscow

M. Stauber, Grumman Aerospace Corporation

L. Stewart, Princeton University

R. Stoller, University of California, Santa Barbara

P. Stone, DOE/Office of Fusion Energy

S. Stynes, Wayne State University

C. Swenson, Iowa State University

F. Tenney, Princeton University

F. Tepe, Jr., University of Cincinnati

F. Thomas, Grumman Aerospace Corporation

A. Tobin, Grumman Aerospace Corporation

W. Vernetson, University of Florida

$\mathrm{K}-\mathrm{W}$. Wang, Southwest Institute of Physics, PEOPLE'S REPUBLIC OF CHINA

R. Werner, Lawrence LIvermore National Laboratory

F. W. Wiffen, Dak Ridge National Laboratory, FEDC

L. Wittenberg, Monsanto Research Corporation

W. Wolfer, University of Wisconsin

D. Young, Jr., University of Texas at Austin

K. Young, Princeton University

M. Youssef, University of California, LA

Library, Centre for Nuclear Studies, FRANCE

Library, Centre de Recherches en Physique des Plasma, SWITZERLAND

Library, FOM-Insitutu voor Plasma-Fysika, NETHERLANDS

Library, Comitato Naxionale per L'energia Nucleare, ITALY

ibrary, Joint Research Centre, ITALY 
Library, Japan Atomic Energy Research Institute, JAPAN

Library, Max Planck Institute fuer Plasmaphysik, FEDERAL REPUBLIC OF GERMANY Library, Culham Laboratory, UNITED KINGDOM

Library, Laboratorio Gas Ionizati, ITALY

A. Opdenaker, Office of Fusion Energy, U. S. Department of Energy 


\section{ACTHONLDEABNS}

The overview presented in this paper is a summary of the work of many scientists and engineers in Europe, Japan, USA, and USSR who participated in the INTOR Study. The INTOR Participants who led the work are: J. Schmidt and M. Abdou (USA), N. Fujlsawa and T. Hiraoka (Japan), M. Harrison and $P$. Schiller (Europe), and V. Pistunovich and G. Shatalov (USSR). The author thanks all members of the USA Impurity Control Engineering Group. 